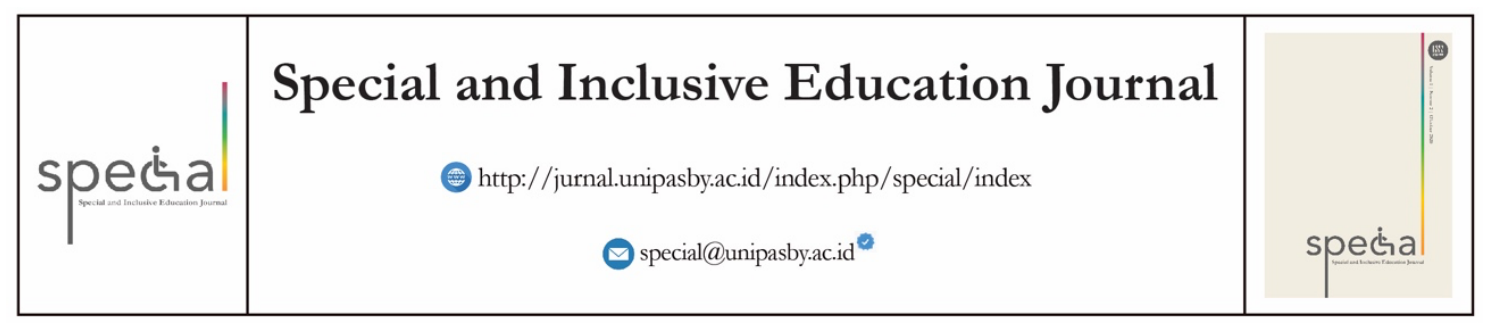

\title{
Penggunaan Media Karaoke Untuk Meningkatkan Kemampuan Menghafal Bacaan Shalat Pada Siswa Tunagrahita Ringan
}

\author{
Sumiyanti \\ sumiyanti1305@gmail.com
}

SLB Negeri Sungailiat

Jl. Pemuda, Parit Padang, Sungai Liat, Kabupaten Bangka, Kepulauan Bangka Belitung 33215

\begin{tabular}{l}
\hline Artikel Info \\
\hline Koresponden penulis : \\
Sumiyanti \\
sumiyanti1305@gmail.com
\end{tabular}

- Diterima 14 Juli 2020

- Direview 31 Oktober 2020

- Disetujui 31 Oktober 2020

- Dipublikasi 31 Oktober 2020

\section{Kata Kunci:}

Tunagrahita, Metode Karaoke, Bacaan Sholat
Keywords:

Mental Retardation, Karaoke Method, Prayer Reading

\begin{abstract}
Abstrak
Siswa tunagrahita ringan mengalami kesulitan dalam menghafal dan mengingat bacaan shalat, namun bukan berarti mereka tidak berpotensi dalam mempelajarinya. Dalam penelitian ini media karaoke sebagai media audiovisual berisikan bacaan shalat yang disertai pelafalan dan gerakannya, untuk membantu pembelajaran menghafal bacaan shalat. Melalui media ini diharapkan dapat meningkatkan kemampuan menghafal bacaan shalat pada siswa tunagrahita ringan secara optimal. Penelitian ini bertujuan untuk memperoleh gambaran mengenai penggunaan media karaoke sebagai media pembelajaran menghafal bacaan shalat pada siswa tunagrahita ringan. Penelitian dilakukan di SLB Negeri Sungailiat Kabupaten Bangka dengan subyek penelitian berjumlah dua orang siswa tunagrahita ringan kelas VI SDLB. Metode yang digunakan adalah eksperimen dengan pendekatan Single Subject Research (SSR) dengan desain A-B-A. Pengumpulan data menggunakan tes lisan berdasarkan 12 indikator kemampuan menghafal bacaan shalat. Perolehan data dianalisis dengan metode inspeksi visual, dengan pengamatan langsung terhadap data dalam grafik. Hasil penelitian menemukan bahwa penggunaan media karaoke sebagai media pembelajaran dapat meningkatkan kemampuan menghafal bacaan shalat pada siswa tunagrahita ringan.

Abstarct
Mental retardation has difficulty memorizing and remembering the prayer
karaoke media as an audiovisual media contains prayer readings accompanied by
pronunciation and movements, to help learning to memorize prayer readings.
Through this media, it is hoped that it can improve the ability to memorize prayer
readings in students with mental retardation optimally. This study aims to obtain
an overview of the use of karaoke media as a learning medium for memorizing
prayer readings in mental retardation students. The research was conducted at SLB
Negeri Sungailiat, Bangka Regency. The research subjects were two students with
mental retardation in grade VI SDLB. The method used is an experiment with the
Single Subject Research (SSR) approach with the A-B-A design. The data were
collected using an oral test based on 12 indicators of the ability to memorize prayer
readings. Acquisition of data was analyzed using visual inspection method, with
direct observation of the data in graphs. The results of the study found that the
use of karaoke media as a learning medium could improve the ability to memorize
prayer readings in mental retardation students.
\end{abstract}




\section{PENDAHULUAN}

Berdasarkan ajaran Nabi Muhammad SAW, rukun dan tatacara shalat harus dilakukan sesuai dengan urutan dan ketentuannya, diantaranya : (1) Bacaan shalat dilafalkan dengan Bahasa Arab; (2) Bacaan berisi do'a-do’a yang ditujukan kepada Allah SWT; (3) Bacaan harus sesuai dengan gerakan shalat yang dilakukan, dll. Menghafal bacaan shalat merupakan suatu usaha untuk menyimpan bacaan shalat ke dalam ingatan. Siswa tunagrahita ringan memiliki rentang ingatan yang cukup pendek, begitu pula dengan kemampuan berbahasa yang lemah. Hal ini memperburuk keadaan dalam mempelajari bacaan shalat, dengan struktur dan pelafalan Bahasa Arab yang jelas berbeda, ditambah pemahaman arti yang abstrak.

Dari hasil studi, peneliti menemukan bahwa lima dari seluruh siswa kelas VI SLB Sungailiat Tahun Ajaran 2014/2015 kurang mampu melafalkan bacaan shalat secara keseluruhan dengan volume suara yang besar. Satu dari lima siswa mampu melafalkan Surat Al-Fatihah, bacaan ruku', bacaan i'tidal, bacaan sujud dan salam. Dua siswa lainnya mampu melafalkan Surat Al Fatihah, bacaan takbir, dan salam, sedangkan dua siswa lainnya hanya mampu melafalkan bacaan takbir yaitu "Allahu akbar". Beberapa dari mereka masih salah dalam melafalkan bacaan yang disertai dengan gerakan shalat. Takbir merupakan satu-satunya bacaan yang paling mudah dan jelas dilafalkan oleh siswa tunagrahita. Lima siswa mengaku bahwa Bahasa Arab sulit diucapkan sehingga membuat anak malas dalam belajar menghafal bacaan shalat.

Media karaoke merupakan video clip lagu yang berisi suara penyanyi dan irama musik, yang biasanya memunculkan bacaan atau lirik lagu. Akan tetapi, untuk pembelajaran shalat media karaoke dirancang dengan berisikan video animasi gerakan shalat disertai suara orang melafalkan bacaan shalat sesuai dengan gerakan shalat, kemudian dimunculkan tulisan bacaan shalat yang semakin tebal setelah dilafalkan. Media karaoke dirancang sedemikian rupa dengan melibatkan respons pengguna secara aktif. Dengan terdapatnya sistem tertentu, pengguna dapat menghilangkan pemutaran suara dan menggantinya dengan suara pengguna. Media karaoke audiovisual memiliki potensi tinggi dalam penyampaian pesan maupun kemampuan dalam menarik minat dan perhatian siswa Fauziah, R. (2020). Dikemukakan oleh Warsito (2008:30) bahwa media berteknologi audiovisual memiliki kemampuan yang efektif (penetrasi lebih dari 70\%) untuk menyampaikan informasi, hiburan, dan pembelajaran. Dengan demikian, peneliti memutuskan untuk menggunakan media karaoke sebagai salah satu media pembelajaran yang efektif.

Apabila media karaoke diterapkan, maka diperkirakan siswa tunagrahita ringan akan tertarik dan fokus pada layar, berkeinginan untuk membaca teks bacaan shalat dan mau untuk melafalkan atau meniru contoh/model yang muncul pada layar. Dengan seringnya siswa menggunakan media karaoke, diharapkan siswa terbiasa melafalkan bacaan shalat dan mudah mengingat hafalan secara keseluruhan. Apabila daya ingat siswa tentang bacaan shalat meningkat, maka kemampuan menghafal bacaan shalat juga meningkat. Sehingga siswa mampu berislam dengan baik. 


\section{METODE PENELITIAN}

Metode yang digunakan dalam penelitian ini adalah metode eksperimen dengan desain penelitian subyek tunggal (Single Subject Research). Penelitian ini dilakukan dengan desain A-B-A yakni penelitian subyek tunggal di bidang modifikasi perilaku yang menunjukkan adanya hubungan sebab akibat antara variabel bebas dan variabel terikat dimana perilaku sasaran subyek (target behavior) diukur terlebih dahulu secara berulang-ulang pada kondisi baseline pertama (A1) dengan periode waktu tertentu, selanjutnya diukur pada kondisi intervensi (B), kemudian diukur kembali pada kondisi baseline yang kedua (A2) sebagai kontrol untuk kondisi intervensi sehingga keyakinan adanya hubungan fungsional antara variabel bebas dan variabel terikat lebih kuat. (Sunanto, et al., 2006:44). Periode waktu (sesi) yang digunakan penelitian ini dilaksanakan perhari. Secara visual, desain A-B-A ini tampak pada gambar di bawah ini :

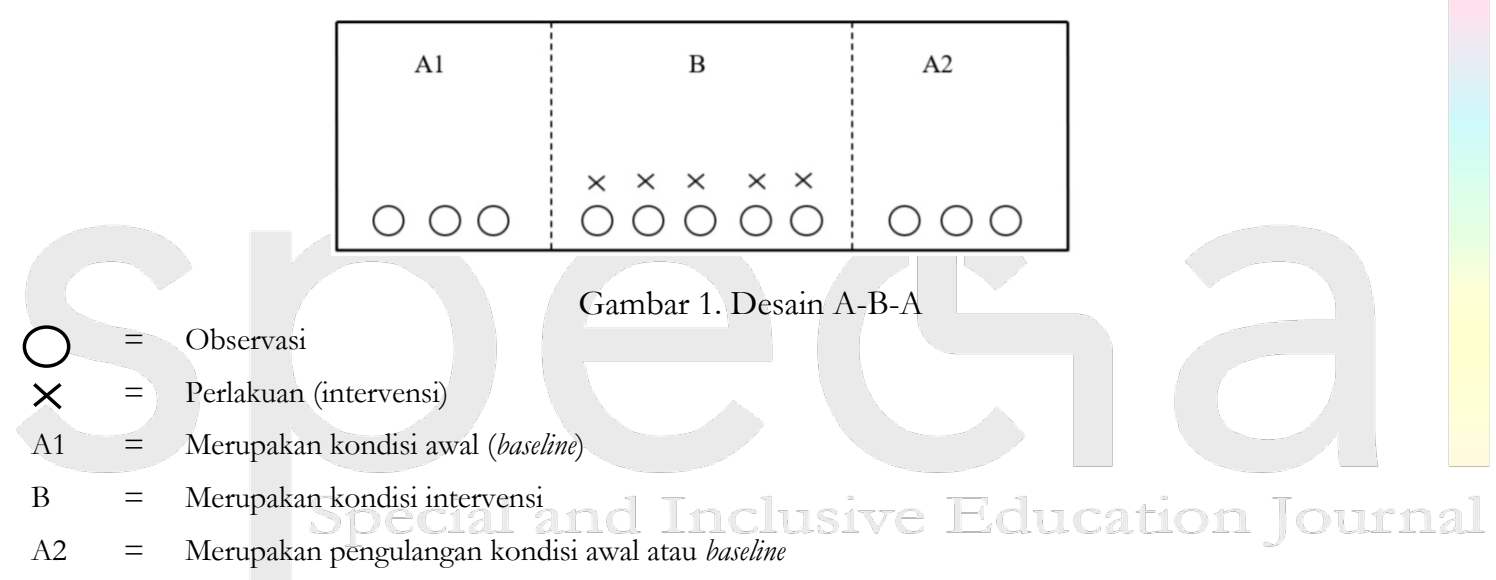

Penelitian ini dilaksanakan di SLB Negeri Sungaliat, Jalan Pemuda, Provinsi Kepulauan Bangka Belitung, dengan subyek dua orang siswa tunagrahita ringan yang belum hafal bacaan shalat namun sudah mampu membaca tulisan latin. Teknik pengumpulan data dalam penelitian ini dengan menggunakan tes lisan yang mengukur kemampuan menghafal bacaan shalat. Metode analisis data penelitian ini menggunakan inspeksi visual, dimana peneliti melakukan pengamatan secara langsung terhadap data yang telah ditampilkan dalam grafik. Secara visual, bentuk dasar grafik tampak pada gambar di bawah ini.

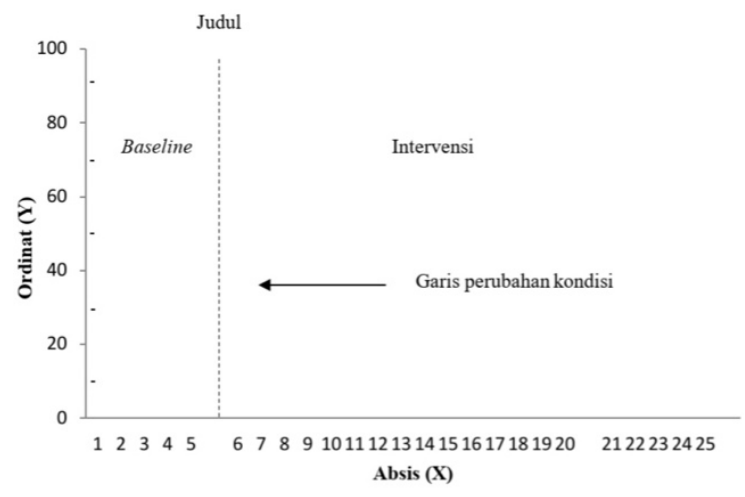

Gambar 2. Grafik pengamatan visual 


\section{HASIL DAN PEMBAHASAN}

Perkembangan kemampuan menghafal bacaan sholat siswa tunagrahita dapat dilihat pada grafik dibawah ini:

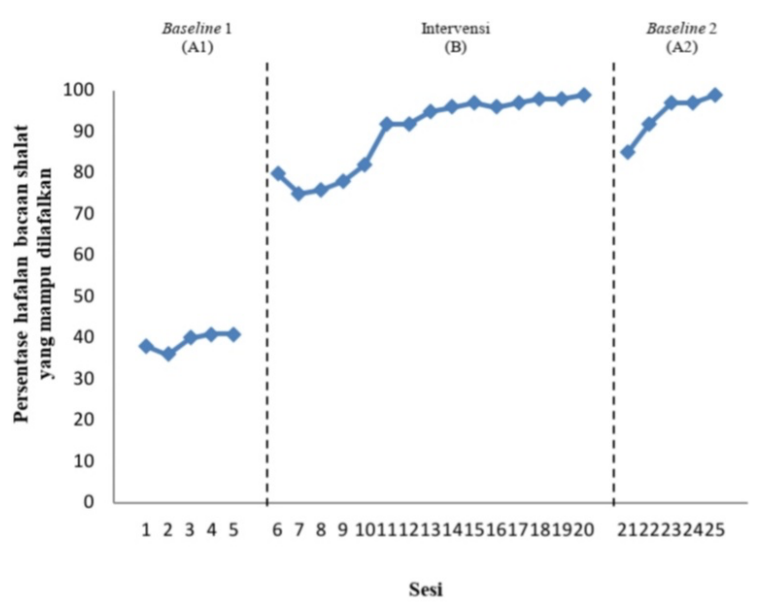

Grafik 2. Perkembangan Kemampuan Menghafal Bacaan Shalat pada Subyek I

Pada Grafik 2, dapat diketahui bahwa fase A1 persentase tertinggi yang diperoleh subyek I di sesi keempat dan sesi terakhir sebesar $41 \%$, sementara persentase terendah berada di sesi kedua sebesar 36\%. Sesi pertama diperoleh subyek I sebesar 38\% dan sesi ketiga sebesar 40\%. Pada fase ini terdapat perubahan kemampuan subyek I dalam melafalkan hafalan bacaan shalat dengan rentang 36-41\%, ini menunjukkan bacaan shalat belum mampu dihafal semuanya. Berdasarkan Grafik 2 pada fase A1 dapat dilihat bahwa subyek I kesulitan dalam menghafal bacaan shalat secara keseluruhan dan sesuai dengan gerakan shalat, sehingga perlu diberikan intervensi.

Pada fase B, persentase tertinggi yang diperoleh subyek I berada di sesi terakhir yaitu sebesar $99 \%$, sementara persentase terendah berada di sesi kedua yaitu sebesar 75\%. Sesi pada fase ini mengalami peningkatan dari fase A1 ke fase B hingga rentang 75-99\%, hal ini menunjukkan adanya perubahan kemampuan menghafal bacaan shalat yang semakin baik, bahkan mendekati sempurna karena bacaan shalat hampir semuanya mampu dihafal dan hafalan tersebut mampu dilafalkan oleh subyek I selama intervensi dilakukan dengan benar, runtun serta sesuai dengan gerakan shalat. Pada fase A2, persentase tertinggi yang diperoleh subyek I berada di sesi terakhir yaitu sebesar 99\%, sementara persentase terendah berada di sesi pertama yaitu sebesar $85 \%$. Rentang data pada fase ini yaitu $85-99 \%$, ini menunjukkan peningkatan jika dibandingkan dengan fase A1 yang persentase tertingginya hanya sebesar $41 \%$.

Berdasarkan analisis data pada fase A1, B, dan A2 menunjukkan perubahan kemampuan yang semakin meningkat dalam menghafal bacaan shalat. Data pada A1 dan B tampak terjadinya perubahan yang sangat signifikan. Kemampuan subyek I dalam melafalkan hafalan bacaan shalat hampir mencapai 100\%. Data fase A2, jika dibandingkan dengan fase B terdapat penurunan, namun hal itu terjadi karena subyek I terlepas dari intervensi. Jika dibandingkan dengan data pada fase A1, maka data A2 mengalami peningkatan tajam, mencapai 99\% dari semua hafalan bacaan shalat yang harus 
dikuasai subyek I sebagai seorang muslim. Dengan demikian, jika dilihat secara keseluruhan perbandingan antara fase A1, B, dan A2 menunjukkan adanya pengaruh penggunaan media karaoke terhadap kemampuan menghafal bacaan shalat pada siswa tunagrahita ringan setelah mendapatkan intervensi.

Kestabilan data pada fase A1 sebesar 100\% yang berarti data stabil dan menandakan intervensi sudah dapat diberikan pada subyek I. Pada fase B, kestabilan data sebesar 47\% yang disebabkan oleh besarnya rentang data dan tingkat variasi skor. Namun, subyek I sudah mencapai persentase hafalan bacaan shalat yang hampir sempurna di lima sesi terakhir, maka peneliti memutuskan untuk melanjutkan ke fase A2. Pada fase A2, kestabilan data sebesar 80\%. Sunanto, et al (2006:68) mengungkapkan bahwa "Jika sebanyak 50\% atau lebih data berada dalam rentang 50\% di atas dan di bawah mean, maka data tersebut dikatakan stabil". Tidak adanya data yang tumpang tindih (overlap) antara fase A1 dengan fase B menunjukkan bahwa proses pembelajaran menghafal bacaan shalat dengan menggunakan media karaoke yang diberikan pada subyek I memiliki pengaruh yang besar yang dapat dilihat pada grafik di bawah ini :

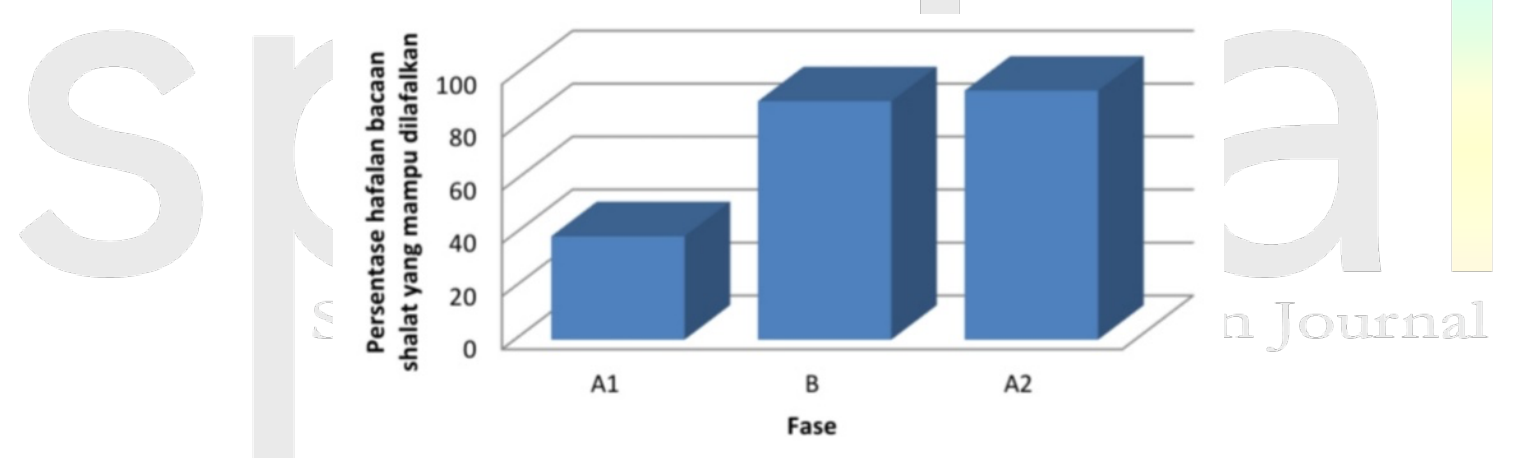

Grafik 3. Mean level Hafalan Bacaan Shalat yang Mampu dilafalkan Subyek I

Pada Grafik 3, adanya peningkatan hafalan bacaan shalat yang dapat dilafalkan subyek I mengarah kepada kemampuan menghafal bacaan shalat subyek I. Data mean level subyek I (AA) hafalan bacaan shalat yang mampu dilafalkan sebagai berikut: 1) Fase A1, 39\%; 2) Fase B, 90\%; dan 3) Fase A2, 94\%. Grafik mean level antar fase menunjukkan adanya peningkatan mean level dari fase A1 ke A2, yaitu sebesar 55\% karena telah diberikannya proses pembelajaran menghafal bacaan shalat dengan media karaoke.

Grafik 4 di atas menunjukkan persentase hafalan bacaan shalat yang dapat dilafalkan oleh subyek II di setiap fase. Pada fase A1 persentase tertinggi yang diperoleh subyek II berada di sesi ketiga sebesar 50\%, sementara persentase terendah berada di sesi pertama sebesar 35\%. Sesi kedua diperoleh subyek II sebesar 42\%, sesi keempat sebesar 45\%, dan sesi kelima sebesar 47\%. Pada fase A1 subyek II mengalami perubahan kemampuan dalam melafalkan bacaan shalat. Rentang datanya sebesar 35-50\%, hal ini menunjukkan subyek II mengalami kesulitan sehingga belum mampu menghafal semua bacaan shalat. 


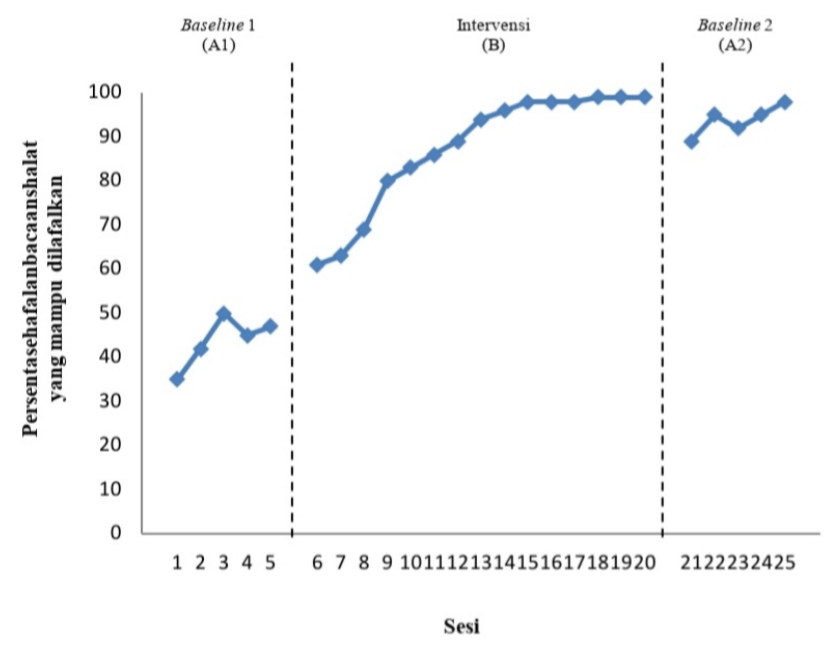

Grafik 4. Perkembangan Kemampuan Menghafal Bacaan Shalat Pada Subyek II

Pada fase B, subyek II tidak berbeda dengan subyek sebelumnya, subyek II mengalami peningkatan, bahkan terjadi di setiap sesinya jika dibandingkan dengan fase A1. Persentase tertinggi yang diperoleh subyek II berada di tiga sesi terakhir yaitu sebesar $99 \%$, sementara persentase terendah berada di sesi pertama yaitu sebesar 61\%. Rentang data pada fase ini yaitu 61-99\%, ini menunjukkan kemampuan menghafal bacaan shalat subyek II menjadi semakin meningkat. Pada fase A2, subyek II mengalami peningkatan dengan persentase tertinggi sebesar $99 \%$, sementara persentase terendah pada sesi pertama sebesar 89\%. Rentang data pada fase ini yaitu $89-99 \%$.

Hasil analisis data pada fase A1, B, dan A2 subyek II menunjukkan perubahan kemampuan yang semakin meningkat dalam menghafal bacaan shalat. Data pada A1 dan B tampak terjadinya perubahan besar yang mana subyek II mengalami peningkatan sebesar 47\%, dan kemampuan dalam melafalkan hafalan bacaan shalat hampir mencapai 100\%. Apabila dibandingkan data fase A2 dengan fase B terdapat penurunan karena subyek I telah terlepas dari intervensi, sedangkan pada fase A1 ke A2 mengalami peningkatan tajam. Secara keseluruhan pada setiap fase, subyek II menunjukkan adanya pengaruh penggunaan media karaoke terhadap kemampuan menghafal bacaan shalat.

Dengan demikian pada fase A1, subyek II memperoleh tingkat stabilitas data sebesar $60 \%$, yang dapat dikatakan stabil. Sedangkan stabilitas pada fase B sebesar 33\% yang berarti data tidak stabil. Hal tersebut terjadi karena rentang data yang cenderung besar dan tingkat variasi data yang sangat tinggi, selain itu subyek telah mencapai persentase sebesar 99\% di tiga sesi terakhir yang berarti kemampuan menghafal bacaan shalat hampir mencapai sempurna (100\%), maka peneliti memutuskan untuk melanjutkan ke fase berikutnya. Pada fase A2, data yang diperoleh sangat stabil dengan tingkat stabilitas sebesar 100\%. Antara fase A1 dengan fase B tidak terdapat data yang tumpang tindih (overlap), mengindikasikan proses pembelajaran menghafal bacaan shalat dengan menggunakan media karaoke berpengaruh kuat terhadap kemampuan menghafal bacaan shalat pada siswa tunagrahita ringan sebagai variabel terikat (target behavior) Mambela, S. (2018). Untuk lebih jelasnya perhatikan grafik di bawah ini. 


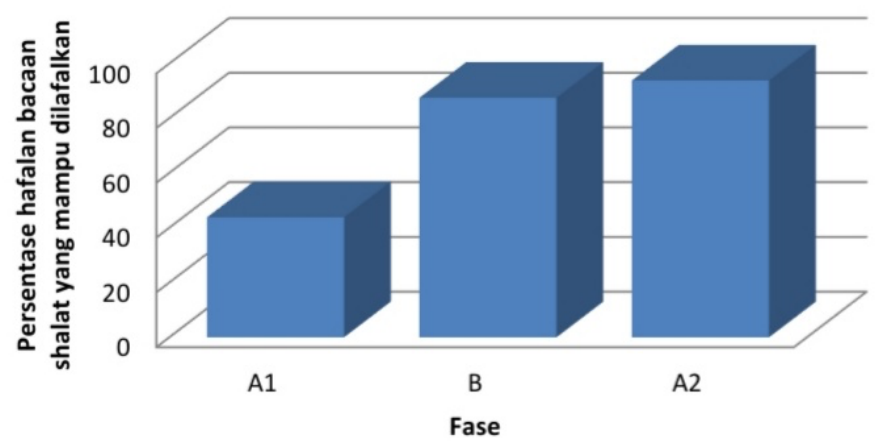

Grafik 5. Mean level Hafalan Bacaan Shalat yang Mampu Dilafalkan Subyek II

Grafik 5 membuktikan adanya peningkatan persentase hafalan bacaan shalat yang dapat dilafalkan subyek II yang mengarah kepada kemampuan menghafal bacaan shalat. Data mean level subyek II (KP) hafalan bacaan shalat yang mampu dilafalkan sebagai berikut : 1) Fase A1, 43,8\%; 2) Fase B, 87,5\%; dan 3) Fase A2, 93,8\%. Dengan mengamati grafik mean level antar fase, maka terlihat adanya peningkatan mean level terutama dari fase A1 ke A2, yaitu sebesar 50\%. Data tersebut menunjukkan bahwa diberikannya proses pembelajaran menghafal bacaan shalat dengan menggunakan media karaoke memiliki pengaruh yang kuat terhadap peningkatan kemampuan menghafal bacaan shalat pada siswa tunagrahita ringan.

Media karaoke sebagai media pembelajaran secara efektif dan efisien dapat meningkatkan kemampuan menghafal bacaan shalat pada siswa tunagrahita ringan Situmorang, R (2020), ditambah lagi isi tayangan media karaoke yang dikembangkan peneliti secara khusus untuk pembelajaran menghafal bacaan shalat menggunakan animasi dengan komposisi warna yang menarik, sehingga dapat menarik perhatian siswa dan memotivasi minatnya untuk belajar Sheikh (2020).

\section{KESIMPULAN}

Penggunaan media karaoke memberikan pengaruh baik pada siswa tunagrahita ringan. Peningkatan kemampuan menghafal bacaan shalat pada kedua subyek ditunjukkan melalui naiknya mean level persentase hafalan bacaan shalat yang mampu dilafalkan dari masingmasing subyek. Setelah intervensi diberikan, mean level subyek I (AA) lebih tinggi 55\%, begitu pula dengan subyek II (KP) mean level setelah diberikan intervensi lebih tinggi 50\%. Dengan demikian masalah penelitian ini dapat terjawab, yaitu: penggunaan media karaoke dapat meningkatkan kemampuan menghafal bacaan shalat pada siswa tunagrahita ringan. 


\section{DAFTAR PUSTAKA}

Fauziah, R. (2020). Pengaruh Media Papan Berpaku Terhadap Hasil Belajar Matematika Pada Materi Bangun Datar Pada Siswa Tunagrahita Kelas II di SLB C1 Putera Asih Kediri. SPECIAL: Special and Inclusive Education Journal, 1(1), 68-73.

Mambela, S. (2018). KEPERAGAAN DALAM MENGATASI ANAK LAMBAN MEMAHAMI PELAJARAN. Buana Pendidikan: Jurnal Fakultas Keguruan dan Ilmu Pendidikan, 14(26), 158-166.

Sheikh, N. A., \& Nadeem, K. (2020). Comparison of seasonal prevalence of Otitis media with effusion (OME) in mentally handicapped versus normal school-going children. The Professional Medical Journal, 27(02), 309-316.

Situmorang, R., Haryanto, E. V., \& Akbar, M. B. (2020). Perancangan Media Pembelajaran Cara Memainkan Seruling 3 Dimensi Berbasis Multimedia. Jurnal Mahasiswa Fakultas Teknik dan Ilmu Komputer, 1(1), 476-488.

Sunanto, J., et al (2006). Penelitian dengan Subyek Tunggal. Bandung: UPI Press.

Warsito, B. (2008). Teknologi Pembelajaran, Landasan dan Aplikasinya. Jakarta: PT. Rineka Cipta. 